\title{
Comparative analysis of the root transcriptomes of cultivated sweetpotato (Ipomoea batatas [L.] Lam) and its wild ancestor (Ipomoea trifida [Kunth] G. Don)
}

\author{
Sathish K. Ponniah', Jyothi Thimmapuram², Ketaki Bhide², Venu (Kal) Kalavacharla,4
} and Muthusamy Manoharan ${ }^{1 *}$

\begin{abstract}
Background: The complex process of formation of storage roots (SRs) from adventitious roots affects sweetpotato yield. Identifying the genes that are uniquely expressed in the SR forming cultivated species, Ipomoea batatas (Ib), and its immediate ancestral species, Ipomoea trifida (It), which does not form SRs, may provide insights into the molecular mechanisms underlying SR formation in sweetpotato.

Results: Illumina paired-end sequencing generated $\sim 208$ and $\sim 200$ million reads for $1 b$ and $/ t$, respectively. Trinity assembly of the reads resulted in 98,317 transcripts for 16 and 275,044 for It, after post-assembly removal of transchimeras. From these sequences, we identified 4,865 orthologous genes in both $I b$ and $I t, 60$ paralogous genes in 16 and 2,286 paralogous genes in It. Among paralogous gene sets, transcripts encoding the transcription factor RKD, which may have a role in nitrogen regulation and starch formation, and rhamnogalacturonate lyase (RGL) family proteins, which produce the precursors of cell wall polysaccharides, were found only in 16 . In addition, transcripts encoding a $\mathrm{K}^{+}$efflux antiporter (KEA5) and the ERECTA protein kinase, which function in phytohormonal regulation and root proliferation, respectively, were also found only in $I 6$. QRT-PCR indicated that starch and sucrose metabolism genes, such as those encoding ADP-glucose pyrophosphorylase and beta-amylase, showed lower expression in It than Ib, whereas lignin genes such as caffeoyl-CoA O-methyltransferase (COMT) and cinnamyl alcohol dehydrogenase (CAD) showed higher expression in It than Ib. A total of 7,067 and 9,650 unique microsatellite markers, 1,037,396 and 495,931 single nucleotide polymorphisms (SNPs) and 103,439 and 69,194 InDels in $I b$ and $I t$, respectively, were also identified from this study.

Conclusion: The detection of genes involved in the biosynthesis of $R G L$ family proteins, the transcription factor RKD, and genes encoding a $\mathrm{K}^{+}$efflux antiporter (KEA5) and the ERECTA protein kinase only in I. batatas indicate that these genes may have important functions in SR formation in sweetpotato. Potential molecular markers (SNPs, simple sequence repeats and InDels) and sequences identified in this study may represent a valuable resource for sweetpotato gene annotation and may serve as important tools for improving SR formation in sweetpotato through breeding.
\end{abstract}

Keywords: Ipomoea batatas, Ipomoea trifida, Storage root, Fibrous root, Transcriptome, Molecular markers

\footnotetext{
* Correspondence: manoharanm@uapb.edu

${ }^{1}$ Department of Agriculture, University of Arkansas at Pine Bluff, Pine Bluff,

Arkansas, USA

Full list of author information is available at the end of the article
} 


\section{Background}

Sweetpotato (Ipomoea batatas [L.] Lam.) is a key food crop worldwide, with high levels of vitamin A and other essential nutrients; sweetpotatoes also produce large quantities of biomass suitable for conversion to bioethanol [1]. Sweetpotato storage roots (SRs) function in carbohydrate storage and vegetative propagation [2, 3] and form from adventitious roots. Adventitious roots develop from nodal primordia and cut ends or wounds of stem (slips) at 5-15 days after transplanting. These adventitious roots can then form SRs by a process that involves thickening of the vascular tissue, followed by the accumulation of starch and proteins [4]. Adventitious roots can also form fibrous roots (FRs), which undergo lignification of the stele; in contrast to FRs, SRs do not undergo stele lignification [4-6]. The conversion of adventitious roots to SRs involves the formation of new cambial cells, followed by the development of secondary cambium and thin-walled parenchyma cells. Despite its importance, key factors in SR development remain to be discovered.

Although the molecular mechanism underlying the transition from adventitious roots to SRs in sweetpotato is not yet clear, substantial prior work has implicated the plant hormones cytokinin, auxin, and abscisic acid (ABA) in the formation and thickening of SRs [7-11]. For example, ABA functions in the secondary thickening of vascular cambium during SR formation in sweetpotato [10]. Transcription factors from various families have also been implicated in SR formation. For example, the transcription factor gene IbMADS1 (Ipomoea batatas MADS-box 1) is expressed during the early stages of SR initiation [12]; also, cytokinins and jasmonic acid induce the expression of IbMADS1. Noh et al. [11] isolated a cDNA encoding the MADS-box protein SRD1, which plays an important role in the formation of SRs by activating the proliferation of cambium and metaxylem cells to induce the initial thickening of SRs. The expression of SRD1 is regulated by the auxin indole-3acetic acid. Also, overexpression of the class I knotted1like homeobox (KNOX1) genes, $I b k n 1$ and $I b k n 2$, results in increased cytokinin activity in sweetpotato, indicating that KNOX1 functions in controlling cytokinin levels in SRs [13].

Expression analysis during SR formation also identified a number of candidate genes [14-16]. For example, You et al. [14] identified 22 differentially expressed genes by comparing early SRs and fibrous roots. Several NAC family transcription factor genes are downregulated in SRs, and two NAM-like genes, as well as sporamin genes and genes involved in starch biosynthesis, are upregulated in SRs (compared to FRs) at six weeks after planting [15]. Noh et al. [16] used antisense RNA interference to demonstrate the negative role of an expansin gene
(IbEXP1) in SR development; IbEXP1 suppresses the proliferation of metaxylem and cambium cells, and thus inhibits the initial thickening of SRs.

Recent work used microarray and next-generation sequencing technologies to examine the molecular mechanism of SR formation in sweetpotato. Wang et al. [17] used microarray analysis to identify transcription factors involved in SR development, such as DA1-related proteins, SHORT-ROOT, and BEL1-like proteins. Using Illumina sequencing, Tao et al. [18] identified genes that are differentially expressed at different stages of sweetpotato root formation. In particular, they found that a gene encoding sucrose phosphate synthase, which functions in sucrose metabolism, is highly expressed in SRs than in fibrous roots. Firon et al. [2] analyzed the root transcriptomes of sweetpotato SRs and nonstorage/fibrous roots and demonstrated that phenylpropanoid pathway genes, such as those encoding coumaroyl CoA-synthase and phenylalanine ammonia lyase, are downregulated during the conversion of FRs to SRs, whereas starch metabolism genes, such as those encoding ADP-glucose pyrophosphorylase and starch synthase, are upregulated in SRs.

The cultivated sweetpotato likely evolved from the wild tetraploid I. trifida and diploid I. trifida/I. tabascana species [19-22]; these wild relatives do not form SRs. Previous transcriptome analyses investigating SR formation examined only the hexaploid cultivated species [2, 23, 24]. Therefore, comparative transcriptome analysis of the wild and cultivated species of sweetpotato may advance our knowledge on the mechanism underlying SR formation in this important crop. In this study, we performed transcriptome analysis of the roots from cultivated sweetpotato (Ib; Ipomoea batatas [L.] Lam) and its non-tuber forming relative (It; Ipomoea trifida [Kunth] G. Don) to elucidate possible pathways and candidate genes involved in SR formation.

\section{Results and discussion \\ De novo assembly of root transcriptomes using Illumina sequencing}

High-throughput sequencing of the root transcriptomes of cultivated Ipomoea batatas (Ib) and its wild ancestor Ipomoea trifida (It) generated 416 and 400 million reads, respectively. All reads were assembled using Trinity (Version r2012-10-15) with default parameters. The maximum contig length was $14,381 \mathrm{bp}$ for $I b$ and $15,897 \mathrm{bp}$ for It (Table 1). The contigs were grouped based on sequence length at an interval of 200 base pairs (bp). The majority of contigs were ranged from 200-399 bp in length $(59.0 \%$ for $I b$ and $66.7 \%$ for $I t)$, followed by $400-599$ bp (14.7\% for $I b$ and $14.1 \%$ for $I t)$. In addition, 25.0 and $18.6 \%$ of the contigs were $600-$ $3000 \mathrm{bp}$ in length for $\mathrm{Ib}$ and $I t$ respectively, and only 
Table 1 Summary of RNA-seq reads from $/ b$ and $/ t$

\begin{tabular}{lllllll}
\hline Genotype & No. of reads (PE, 2x100) & No. of contigs & $N_{50}$ contig length & Min. length of contigs & Max. length of contigs & Filtered transcripts $^{a}$ \\
\hline I. batatas (Ib) & $208,213,047$ & 240,915 & 1,791 & 201 & 14,381 & 98,317 \\
I. trifida (It) & $200,191,376$ & 366,513 & 1,217 & 201 & 15,897 & 275,044
\end{tabular}

${ }^{a}$ Selected highly covered isoforms using RSEM and post-assembly trans-chimera cleanup using BLASTX results against the non-redundant protein database

$1.3 \%$ of the contigs in $I b$ and $0.6 \%$ of the contigs in $I t$ were $>3000$ bp long (Figs. 1 and 2).

\section{Functional annotation by sequence comparison with public databases}

To perform functional annotation of the $I b$ and $I t$ contigs, we used BLASTX [25] with a cutoff e-value of $1.0 \mathrm{E}-3$ to search public databases, such as the nonredundant (nr), Arabidopsis, cassava, and potato databases, and the sweetpotato gene index. This analysis showed that $44.1 \%$ of $I b$ transcripts and $63.8 \%$ of $I t$ transcripts matched the non-redundant (nr) database, but only $33.0 \%$ of $I b$ and $32.7 \%$ of $I t$ transcripts matched the Arabidopsis database. Similarity searches of the sweetpotato gene index revealed matches of only $25.7 \%$ and $8.7 \%$ of transcripts for $I b$ and $I t$, respectively. The low percentage of $I b$ and $I t$ transcripts with sequence similarity to sweetpotato gene index may be attributed to the limited number of annotated genes in the database. Searches of the potato and cassava databases also showed the same degree of similarity as found for searches of the Arabidopsis database (Table 2). Overall, $51.7 \%$ of the transcripts from $I b$ and $66.4 \%$ of the transcripts from It showed homology with at least one database. The detailed functional annotation for each species is presented in Additional files 1 and 2.

\section{Comparative analysis of gene sets between $I b$ and $I t$}

To allow direct comparison of loci between $I b$ and $I t$, we used the annotated transcripts to identify orthologous and paralogous genes in $I b$ and $I t$. Among the 60 paralogous gene sets with 148 contigs identified in $I b, 18$ contigs had no match in the Arabidopsis database, whereas the remaining 130 transcripts that matched with the Arabidopsis database were found to be involved in cellular organization, membrane transport, glucose metabolic activity, and carbohydrate metabolism. However, none of the 60 paralogous gene sets identified in $I b$ had matches in the sweetpotato gene index, most likely due to the small number of annotated genes available in this database (Additional file 3). In $I t$, we identified 2,286 paralogous gene sets with 9,585 contigs. Among 9,585 contigs, 4,890 contigs had no match in the Arabidopsis database; the remaining 4,695 transcripts, which matched with the Arabidopsis database, were involved in transporter activity, stress-related functions, and ribosomal proteins involved in translation. In contrast, only 72 transcripts, which matched with sweetpotato gene index, showed annotated gene functions (Additional file 4). We also identified 5,695 and 6,289 transcripts in $I b$ and $I t$, respectively, from 4,865 orthologous gene sets. Examples of orthologous genes include calcium-dependent lipid binding (CaLB) domain and the porcino tubulin-binding cofactor, which are involved in stress and defense responses. CaLB-domain

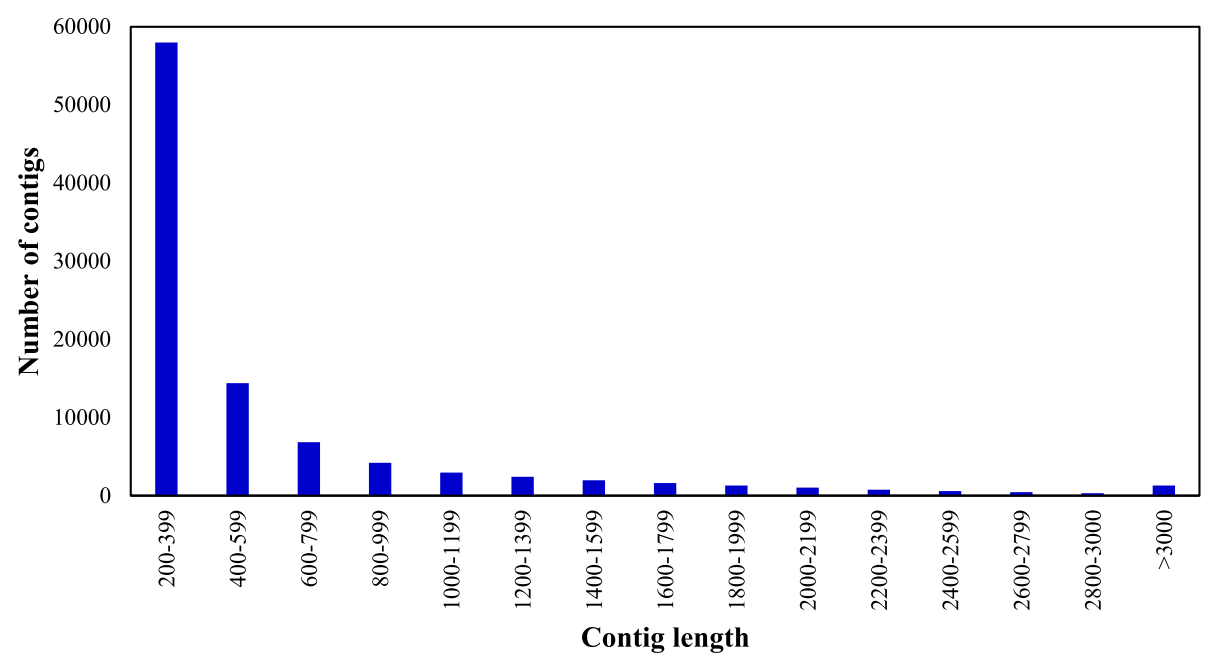

Fig. 1 Length distribution of I. batatas contigs. Total reads were assembled using Trinity and grouped based on sequence length at 200-bp intervals 


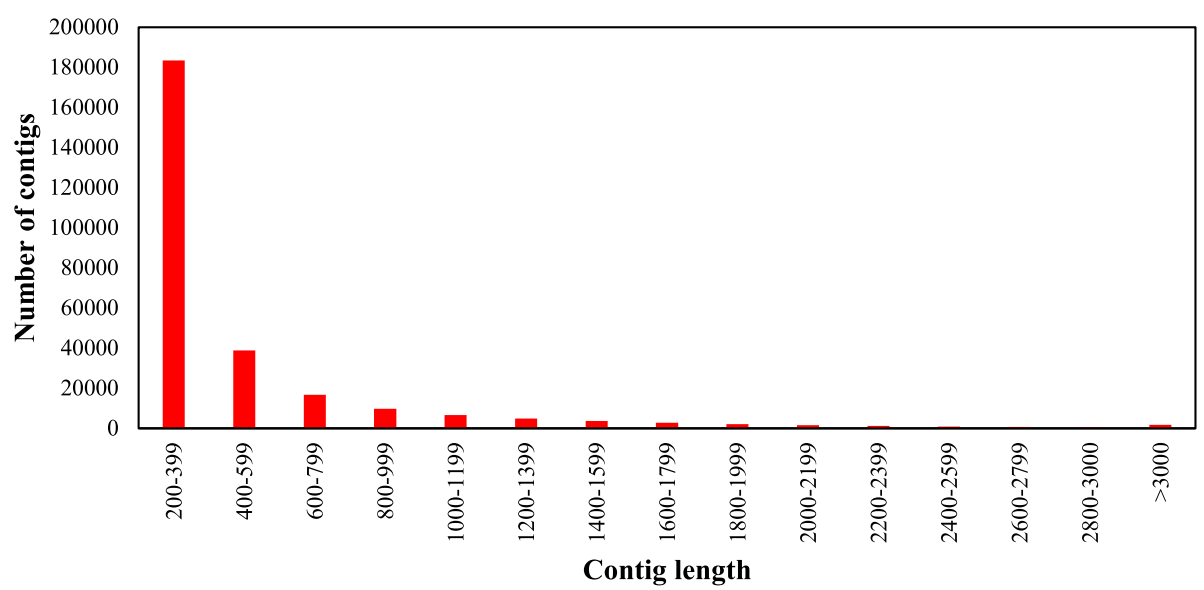

Fig. 2 Length distribution of I. trifida contigs. Total reads were assembled using Trinity and grouped based on sequence length at 200-bp intervals

genes are upregulated in drought-stressed sweetpotato [26]. The transcription factors observed among the orthologs include KNOX, BEL-1 like homeodomain, and NAC domain-containing proteins that are involved in DNA binding and transcription activities. In sweetpotato, KNOX1 is involved in secondary thickening of the SRs through enhanced cytokinin activity [13] and BEL-1 like homeodomain involved in SR development [17]. The NAC domain-containing proteins are upregulated in sweetpotato SRs compared to fibrous roots [15]. Overall, the orthologous genes and transcription factors in both $I b$ and $I t$ are involved in activities such as nucleic acid binding, defense responses, cell division and differentiation, transport, root gravitropism, hormonal control, and glucose metabolism (Additional file 5).

Among paralogous gene sets, genes encoding the rhamnogalacturonate lyase $(R G L)$ family proteins, $\mathrm{K}^{+}$efflux antiporter (KEA5), and ERECTA protein kinases were found only in $I b$. RGL proteins comprise the major components of pectin polysaccharides in the cell wall [27]. $R G L$ proteins also serve as signaling molecules for pectin polysaccharides [28], and are involved in cell wall modifications such as cell wall expansion, porosity, and textural changes during fruit ripening [29-32]. In Arabidopsis, the

Table 2 BLAST annotation of $I b$ and $/ t$ transcripts

\begin{tabular}{lll}
\hline Number of transcripts with matches in: & lb & It \\
\hline Sweetpotato gene index & 25,258 & 23,909 \\
NCBI nr database & 43,369 & 175,495 \\
Arabidopsis database & 32,427 & 89,972 \\
Cassava database & 33,006 & 90,308 \\
Potato database & 33,335 & 87,150 \\
At least one database & 50,860 & 182,692 \\
No matches in any database & 47,457 & 92,352 \\
Information in Trinotate & 11,237 & 25,068 \\
\hline
\end{tabular}

expression of $R G L$ genes, which are involved in lateral root and root hair formation, is altered in response to the inhibition of primary root growth [33]. Also, in potato (Solanum tuberosum), overexpression of RGL genes leads to distinct morphological changes in the cortex and periderm [34]. The expression of RGL genes (with FPKM (Fragments per Kilobase of Exon per Million Fragments Mapped) value of 181.1) only in $I b$ suggests that pectin polysaccharides may play a role in cell expansion leading to the accumulation of storage proteins in developing SRs and that $R G L$ proteins may have important roles in the secondary thickening of cell walls.

$\mathrm{K}^{+}$(KEA5) transporter genes (with FPKM value of 14.9) are another group of genes that are expressed specifically in $I b$. These transporters are involved in stomatal activity, leaf movements, ion transport, and the regulation of phytohormones such as auxin, ethylene, and jasmonic acid [35, 36]. $\mathrm{K}^{+}$transporters also play an important role in cell expansion associated with turgor pressure in Arabidopsis [37, 38]. The expression of $K E A 5$ transporter genes in $I b$ suggests that they may play a role in SR formation through the regulation of phytohormones such as auxin. In plant roots, auxin regulates lateral root development and gravitropism [39]. In sweetpotato, auxin regulates the expression of the transcription factor SRD1, which is involved in SR formation [11]. Therefore, the coordinated regulation of transporter genes such as KEA5 and transcription factors such as $S R D 1$ in auxin regulation may be a possibility during SR formation in sweetpotato. In the present study, in addition to RGL family genes and KEA5, ERECTA protein kinase (with FPKM value of 2.2) was also identified in the paralogous genes of $I b$ but not in It. ERECTA protein kinase is a leucine-rich repeat receptor-like kinase (LRR-RLK) involved in the proliferation of organelles. ERECTA protein kinases regulate organ shape and inflorescence development in Arabidopsis [40, 41]. Interestingly, receptor-like 
kinases are involved in lateral root development in Arabidopsis [42] and cell wall-bound kinases are associated with pectin binding in Arabidopsis [43]. ERECTA, along with $R G L$ family proteins, might represent an important link between the regulation of cell wall structure and SR development in sweetpotato. Among the transcription factors in paralogous genes, $R K D$ (RWP-RK domain) belongs to the RWP-RK domain-containing proteins, which are involved in DNA binding and regulation of transcription activity, were expressed in $I b$ but not in $I t$. The RWP-RK protein domain is required for embryonic pattern formation [44] and plays a key role in regulating responses to nitrogen availability [45]. Recent work reported that NIT2, a member of the RWP-RK family, influences starch and lipid storage in Chlamydomonas [46]. In Arabidopsis thaliana, NLP7, another member of the RWP-RK family, is an early regulator of cellular response to nitrogen assimilation [47]. The unique expression of RWP-RK proteins (with FPKM value of 18.4) only in $I b$ indicate that these proteins may have a role in nitrogen regulation and starch formation during the development of sweetpotato SRs.

\section{Expression of genes involved in SR formation}

We compared the expression of genes in $I b$ versus $I t$ based on their respective FPKM values (Table 3). Although two species were compared to estimate upor down-regulation of gene expression, a clear limitation in our study is the lack of biological replications. Therefore, conclusions reached in this study, may change in future experiments with biological replications. While hundreds or thousands of mapped reads of differentially expressed genes are likely to be reliable, careful reading is required for the contigs/transcripts with few mapped hits. Some evidence for this differential gene expression is supported by the qRT-PCR results (Fig. 3). In the present study, the class-I knotted1-like homeobox gene KNOX1 was highly expressed in $I b$ (136.9) compared to

Table 3 Comparison of annotated genes involved in storage root formation between $I b$ and It using FPKM values

\begin{tabular}{llll}
\hline Annotation & Ib & It & Ratio \\
\hline Sporamin & $56,838.3$ & 15.2 & 3739.4 \\
Expansin & 70.5 & 10.9 & 6.5 \\
Glucose-1-phosphate adenylyltransferase & 1745.2 & 178.7 & 9.8 \\
Alpha-1,4 glucan phosphorylase & 1305.1 & 0.5 & 2610.2 \\
Beta-amylase & 381.7 & 28.6 & 13.3 \\
Phosphoglucomutase & 170.2 & 76.7 & 2.2 \\
Class-I knotted1-like homeobox protein & 136.9 & 50.3 & 2.7 \\
lbKN2 (KNOX) & & & \\
ADP-glucose pyrophosphorylase & 1752.6 & 178.7 & 9.8 \\
Starch synthase & 110.0 & 15.9 & 6.9 \\
\hline
\end{tabular}

It (50.3). Similarly, Firon et al. [2] observed the increased expression of KNOX1 in developing sweetpotato SRs versus FRs. KNOX1 is also associated with higher cytokinin levels, in addition to secondary thickening, in sweetpotato SRs $[13,14]$. The cell wall loosening protein expansin was highly represented in $I b$ (70.5) compared to It (10.9). Firon et al. [2] demonstrated the involvement of this expansin gene in the initiating SRs of sweetpotato. Also, the gene encoding the sporamin was highly expressed in $I b(56,838.3)$ than in $I t(15.2)$ (Table 3). Sporamin, a key storage protein in sweetpotato SRs [15], forms in the endoplasmic reticulum, and the mature sporamin moves to the vacuoles of SRs [48]. In sweetpotato, sporamin was accounted for over $80 \%$ of the total protein in the SRs [49] and highly expressed in SRs than in FRs [2]. The high expression of sporamin in $I b$ confirmed its role in the synthesis of storage proteins. In the present study, starch and sucrose metabolic genes, such as $\beta$-amylase (381.7), glucose-1-phosphate adenylyltransferase (1745.2), phosphoglucomutase (170.2), starch synthase (110.0), ADP-glucose pyrophosphorylase (1752.6), and alpha 1-4 glucan phosphorylase (1305.1) were highly expressed in $I b$. Similar to our study, the high expression of the gene encoding $\beta$-amylase is observed in the initiating SRs compared to fibrous roots in sweetpotato [2]. Also, the increased expression of ADP-glucose pyrophosphorylase is associated with starch accumulation in sweetpotato SRs [18]. Clearly, the high expression of both $\beta$-amylase, the second most abundant storage protein in sweetpotato after sporamin [48], and ADP-glucose pyrophosphorylase is positively correlated to their role in starch biosynthesis in sweetpotato [50]. In the present study, we observed higher expression of the gene encoding phosphoglucomutase in $I b$ than in $I t$, indicating that the enhanced activity of this enzyme may provide abundant substrate for ADP-glucose pyrophosphorylase, the first step in starch biosynthesis pathway. Indeed, enhanced expression of phosphoglucomutase was previously observed in the SRs of sweetpotato [2]. Another highly expressed gene in $I b$ encodes alpha 1-4 glucan phosphorylase, an enzyme involved in starch phosphorylation in Arabidopsis [51]. The phosphorylation of starch promotes the accumulation of starch granules in the SRs of sweetpotato [18]. The high expression of genes encoding phosphoglucomutase and alpha 1-4 glucan phosphorylase in $I b$ reflects the high activity of starch metabolic genes in SRs.

\section{Expression of genes involved in non-storage/fibrous root formation}

We compared the expression of genes in $I t$ versus $I b$ based on their respective FPKM values (Table 4). The results indicate that genes encoding cysteine protease (1709.6), cysteine proteinase (744.9), ethylene responsive 


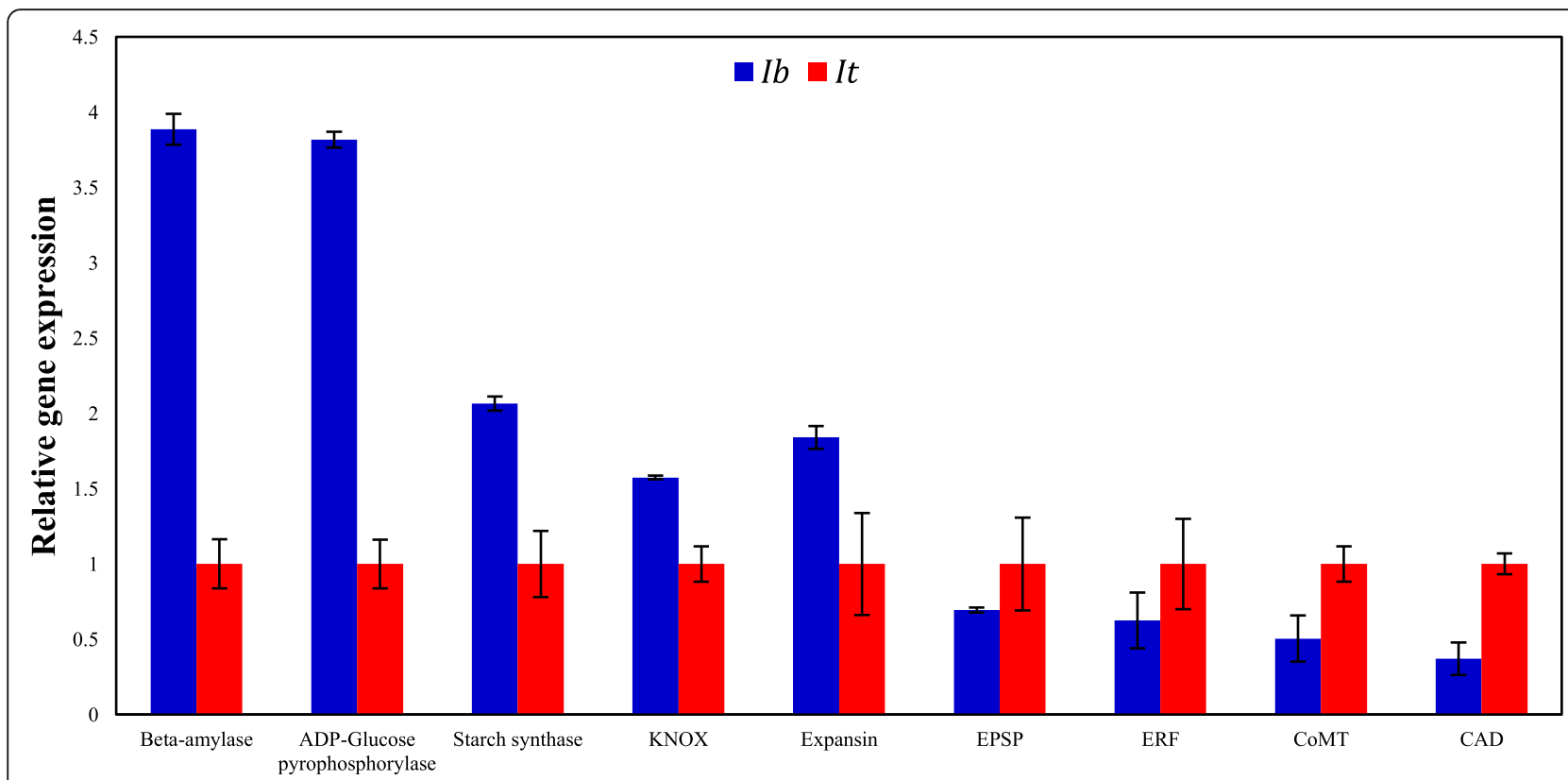

Fig. 3 Validation of relative expression levels of selected genes (qRT-PCR). Expression levels were compared between I. batatas (Ib; indicated in blue) and I. trifida (It; indicated in red). Quantitative RT-PCR was performed with three biological replicates and two technical replicates for both $I b$ and $I t$. The sweetpotato $\beta$-tubulin gene was used as an endogenous control and the gene expression levels were determined using the $\Delta \Delta C t$ method. Genes are shown with respective TAIR locus IDs: $\beta$-amylase (AT4G15210); ADP-glucose pyrophosphorylase (AT4G39210); Starch synthase (AT4G18240); KNOX: class I Knotted-like homeobox (AT4G08150); Expansin (AT2G39700); EPSP: 5- enolpyruvylshikimate-3-phosphate synthase (AT2G45300); ERF: Ethylene-responsive transcription factor (AT1G50640); CoMT: caffeoyl-CoA O-methyltransferase (AT4G34050); CAD: cinnamyl alcohol dehydrogenase (AT1G72680)

transcription factor $(E R F)$ (211.8), osmotin-like proteins (787.7), and peroxidase (689.3) were highly expressed in It. Cysteine protease is involved in the degradation of sporamin in sprouting sweetpotato SRs [52]. In addition, the cysteine protease gene is downregulated in sweetpotato SRs [2]. In our study, a cysteine protease gene was highly expressed in $I t$, indicating that this enzyme may prevent the accumulation of sporamin in the roots and helps them remain as fibrous roots. Cysteine proteinases

Table 4 Comparison of annotated genes involved in fibrous root formation between $I b$ and It using FPKM values

\begin{tabular}{llll}
\hline Annotation & Ib & It & Ratio \\
\hline Cysteine protease & 44.9 & 1709.6 & 38.1 \\
Cysteine proteinase & 145.4 & 744.9 & 5.1 \\
Osmotin-like protein & 20.4 & 787.7 & 38.6 \\
Succinate dehydrogenase & 41.9 & 49.0 & 1.2 \\
Caffeoyl-CoA O-methyltransferase (COMT) & 410.7 & 975.2 & 2.4 \\
Phenylalanine ammonia-lyase (PAL) & 87.3 & 443.0 & 5.1 \\
Peroxidase & 105.5 & 689.3 & 6.5 \\
4-coumarate-CoA ligase (4-CL) & 30.3 & 198.7 & 6.6 \\
Cinnamyl alcoholdehydrogenase (CAD) & 67.7 & 762.9 & 11.3 \\
5-enolpyruvylshikimate-3-phosphate & 29.1 & 144.3 & 5.0 \\
synthase (EPSP) & & & \\
Ethylene responsive transcription factor (ERF) & 77.9 & 211.8 & 2.7 \\
\hline
\end{tabular}

also exhibit protein degradation activity [53]. The cysteine proteinase gene is upregulated in FRs compared to the SRs in sweetpotato [2]. We observed similar high expression of the cysteine proteinase gene in $I t$, indicating that this enzyme may be involved in proteolytic activity and promotes the development of FRs. Genes encoding osmotin-like protein were highly expressed in It compared to $I b$ (Table 4). The osmotin-like proteins are plant defense proteins [54] that regulate the production of jasmonic acid and ethylene in Arabidopsis [55]. In sweetpotato, the osmotic-like stress response genes are downregulated in the SRs compared to FRs [2]. The ethylene responsive transcription factor $(E R F)$ was highly expressed in $I t$ than $I b$, indicating the activity of this stress-responsive gene in the fibrous roots. Likewise, genes encoding peroxidase showed decreased expression in $I b$ versus $I t$, indicating that peroxidase genes may be involved in phenylpropanoid and lignin (polymerization) biosynthesis pathways [2]. Another stress-response gene, which encodes succinate dehydrogenase, was minimally increased in $I t$ versus $I b$; succinate dehydrogenase functions in the production of reactiveoxygen species during stress-related activities [56]. Overall, the higher expression of proteolytic enzymes such as cysteine protease and cysteine proteinase in It indicates that these genes may prevent the accumulation of storage proteins in the developing FRs. Moreover, the higher 
expression of stress-response genes such as those encoding peroxidases promotes the expression of phenylpropanoid pathway genes and the accumulation of lignin in FRs in sweetpotato [2].

In addition, lignification helps roots remain as nonstorage/fibrous roots and prevents the conversion of fibrous roots to SRs. In the current study, we observed higher expression of genes encoding phenylpropanoid and lignin biosynthetic enzymes, such as 5-enolpyruvylshikimate-3 phosphate (EPSP) synthase (144.3), phenylalanine ammonia-lyase $(P A L)$ (443.0), 4-coumarate-CoA ligase (4-CL) (198.7), cinnamyl alcohol dehydrogenase $(C A D)$ (762.9), peroxidase (689.3), and caffeoyl-CoA O-methyltransferase (CoMT) (975.2) in It (Table 4). The enzyme EPSP synthase produces an important precursor in the shikimate pathway, promotes the synthesis of lignin and phenylalanine [57]. Consistent with our observations, other studies showed that in sweetpotato, genes encoding cinnamyl alcohol dehydrogenase, coumaroyl-CoA synthase, and caffeoyl-CoA Omethyltransferase are downregulated during SR initiation [2]. Moreover, lignin biosynthesis genes are upregulated in the early stages of fibrous root formation in sweetpotato [17]. The increased expression of the phenylpropanoid and lignin genes in It provides evidence for the accumulation of lignins during FR development.

\section{Validation of gene expression through quantitative reverse-transcription PCR (qRT-PCR)}

We profiled different genes, based on FPKM values, for expression in $I b$ and $I t$ with the RNA samples used for Illumina sequencing. Genes involved in starch and sucrose metabolism, and lignin biosynthesis, such as those encoding ADP-glucose pyrophosphorylase, $\beta$-amylase, starch synthase, cinnamyl alcohol dehydrogenase $(C A D)$, and caffeoyl-CoA O-methyltransferase (CoMT) were selected for qRT-PCR. The genes and their respective primers are presented in Additional file 6. The qRT-PCR results indicated the starch metabolic genes such as ADPglucose pyrophosphorylase, beta-amylase, and starch synthase were highly expressed in $I b$ than in It (Fig. 3). The high expression of starch metabolism genes in $I b$ reflects the movement of storage proteins during SR development. A similar finding for starch metabolism genes was previously reported in sweetpotato [2]. The qRT-PCR results showed that the gene encoding expansin was more highly expressed in $I b$ than in It. By contrast, Noh et al. [16] found that the expression of the expansin gene is inhibited during SR formation in sweetpotato. However, Firon et al. [2] demonstrated that the expansin gene is involved in SR formation in sweetpotato. In the present study, the meristematic regulatory gene $K N O X 1$ was highly expressed in $I b$, which was previously demonstrated in the development of sweetpotato
SRs [13]. The qRT-PCR results showed that the gene ethylene response factor $(E R F)$ was expressed at higher levels in $I t$ than in $I b$. By contrast, Firon et al. [2] showed high expression of ERF in sweetpotato SRs compared to FRs of the cultivar Georgia Jet. The shikimate pathway gene encoding EPSP synthase was highly expressed in It. This enzyme forms an important precursor in the shikimate pathway and promotes the biosynthesis of lignin [57]. The qRT-PCR results showed that the lignin biosynthetic genes $C A D$ and CoMT were highly expressed in It compared to $I b$. In summary, the high expression of starch and sucrose metabolism genes in $I b$ promotes SR formation, whereas the high expression of lignin biosynthetic genes in $I t$ promotes the development of FRs/non-storage roots.

Functional classification of transcripts using Gene Ontology (GO) and pathway analysis

The $I b$ and $I t$ annotated transcripts were grouped into three biological functions such as biological process, molecular function, and cellular component using the GO Slim database [58]. The majority of GO annotations ( $47.7 \%$ in $I b$ and $46.6 \%$ in $I t$ ) were grouped into the biological process category, followed by molecular function (27.8\% in $I b$ and $25.6 \%$ in $I t)$. In addition, $24.5 \%$ of $I b$ and $27.8 \%$ of It transcripts were grouped in the cellular component category (Fig. 4; Additional files 1 and 2). Most transcripts in the biological process category are involved in oxidation-reduction processes, protein phosphorylation, regulation of transcription, metabolic processes, salt stress, and signal transduction and translation. The transcripts in the molecular function category are involved in ATP binding, protein binding, DNA binding, phosphorus transferase, and catalytic activity. The transcripts grouped within the cellular component category were based on their predicted sub-cellular locations in the nucleus, plasma membrane, chloroplast, cytoplasm, extracellular space, and vacuole. Similar groupings of annotated genes have been reported in previous sweetpotato root transcriptome studies [2, 24].

The annotated transcripts between $I b$ and $I t$ were assigned to various biological pathways using DAVID $[59,60]$. A total of $32,427(33.0 \%)$ and $89,972(32.7 \%)$ transcripts were assigned to 365 and 371 pathways in $I b$ and $I t$ respectively. Further, we also examined the pathways that are differentially enriched in $I b$ and $I t$. The enriched transcripts in $I b$ and $I t$ (percentage of expressed transcripts) showed 16 major pathways that are involved in storage/fibrous roots (Fig. 5). The list of transcripts and KEGG-enriched pathways from DAVID are presented in Additional files 7 and 8. In $I b$, we observed a higher percentage of differentially expressed transcripts in the starch (77 transcripts, $0.002 \%$ of the expressed transcripts) and sucrose biosynthetic pathways 


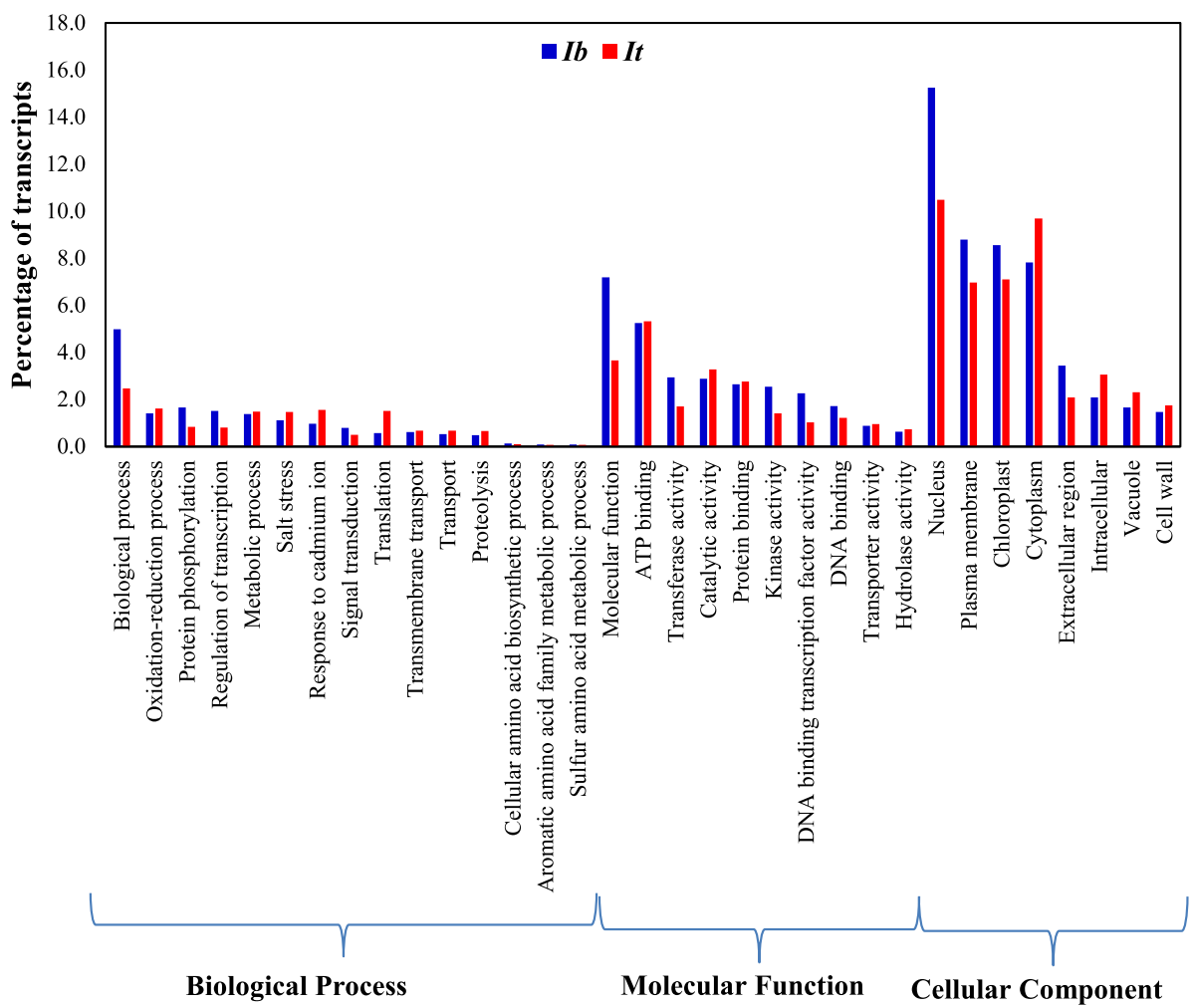

Fig. 4 Functional classification of transcripts using Gene Ontology. I. batatas (Ib) transcripts are indicated in blue, and I. trifida (It) transcripts are indicated in red. The non-redundant transcripts were subjected to functional classification using GOSlim

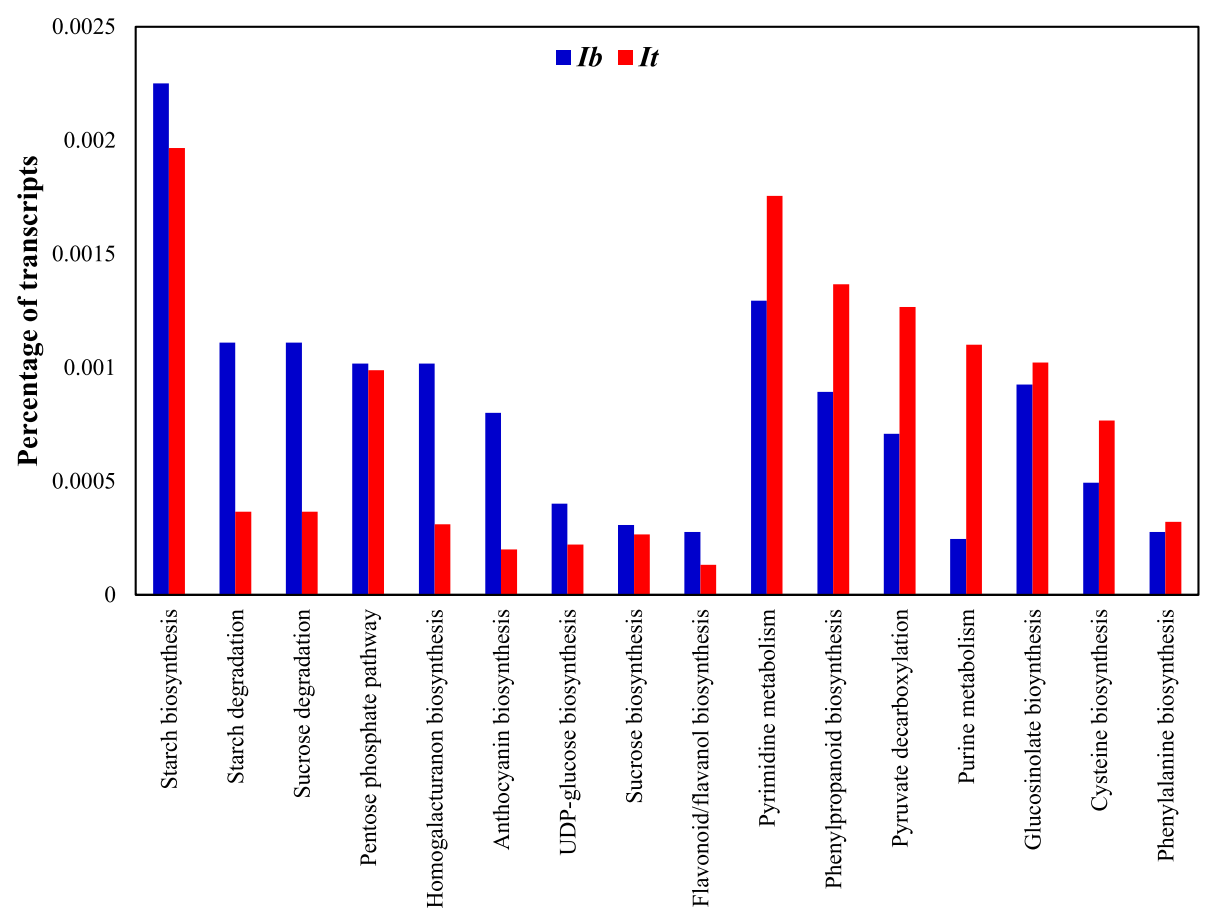

Fig. 5 Functional classification of transcripts using DAVID. I. batatas (Ib) transcripts are indicated in blue, and $I$. trifida (It) transcripts are indicated in red. The functional grouping was based on KEGG pathway names associated with transcripts from DAVID analysis 
(10 transcripts, $0.001 \%$ ) compared to It (177 transcripts, $0.001 \%$ in starch, and 24 transcripts, $0.0002 \%$ in sucrose biosynthetic pathways). The increased expression of sucrose and starch metabolic genes indicated the synthesis of sucrose and starch in the storage roots [2]. We also detected a large percentage of transcripts in $I b$ (13 transcripts, $0.0004 \%$ ) than in It (20 transcripts, $0.0002 \%$ ) for UDP-glucose biosynthesis, which is involved in the synthesis of UDP glucose. The increased expression of transcripts for UDP-glucose biosynthesis in $I b$ indicates the increased activity of UDP sugars in the storage roots. In $I b$, enrichment of transcripts involved in the homogalacturonan pathway (33 transcripts, $0.001 \%$ ) was observed in comparison with It (28 transcripts, 0.0003\%), which indicates the accumulation of pectins in the storage roots. The pectin in the primary cell walls forms from homogalacturonans, rhamnogalacturonan-I, and rhamnogalacturonan-II [28], and strengthens the cell wall of the developing SRs.

The percentage of transcripts of secondary metabolic pathways such as the anthocyanin (26 transcripts, $0.0008 \%$ ) and flavonoid biosynthetic pathways (9 transcripts, $0.0003 \%$ ) were more represented in $I b$ than $I t$ (18 transcripts, $0.0002 \%$, and 12 transcripts, $0.0001 \%$ ). This is in contrast to the results of Firon et al. [2] who reported higher expression of anthocyanin and flavonoids in FRs than in SRs of sweetpotato. The more representation of anthocyanin and flavonoids in our study could be due to the use of orange-fleshed Beauregard variety. Earlier transcriptome studies showed that genes related to production of anthocyanin and flavonoid compounds were highly expressed in purple and yellowcolored sweetpotato SRs [61].

The transcripts representing the phenylpropanoid pathway (123 transcripts, $0.001 \%$ ) and phenylalanine biosynthesis (29 transcripts, $0.0003 \%$ ) were more represented in $I t$ than $I b$ (29 transcripts in $I t, 0.0008 \%$, and 9 transcripts in $I b, 0.0002 \%)$ indicating the synthesis of lignin in the fibrous/non-storage roots. Similar results of higher phenylalanine biosynthesis were observed in the FRs of sweetpotato [2]. Transcripts of the pyruvate decarboxylation pathway were also more represented in It (114 transcripts, $0.001 \%)$ than $I b$ (23 transcripts, $0.0007 \%)$. The pyruvate decarboxylation pathway participates in carbohydrate metabolism and down-regulates the synthesis of glucose. In sweetpotato, Firon et al. [2] demonstrated the downregulation of pyruvate decarboxylase in the SRs in comparison with the FRs. We also observed more representation of transcripts related to biosynthesis of glucosinolate (92 transcripts, $0.001 \%$ ) and cysteine (69 transcripts, $0.0007 \%$ ), which are involved in stress and defense responses, in It compared to $I b$ (30 transcripts, $0.0009 \%$, and 16 transcripts, 0.0004\%). In Arabidopsis, the expression of glucosinolate occurs in the antifungal defense response [62]. In sweetpotato, Firon et al. [2] showed the high representation of cysteine biosynthesis genes, consistent with the results of our study, in the non-storage/fibrous roots. In addition, transcripts of purine and pyrimidine metabolism, which are involved in the synthesis of nucleic acids and energy carriers in the cell [63], were more represented in It (99 transcripts, $0.001 \%$, and 158 transcripts, $0.002 \%$ ) than $I b$ (8 transcripts, $0.0002 \%$, and 42 transcripts, $0.001 \%$ ).

\section{Identification of Simple Sequence Repeat (SSR) markers}

We predicted potential microsatellite markers based on the assembled transcripts generated from $I b$ and $I t$ using SSRfinder [64] and MISA (Version 1.0) [65]. We mined for new microsatellite markers in $I b$ and $I t$ using 98,317 and 275,044 transcripts, respectively. A total of 20,065 and 26,158 microsatellite markers were identified in $I b$ and $I t$, respectively (Table 5). The list of identified SSRs, along with the associated forward and reverse primers are presented in Additional file $9(\mathrm{Ib})$ and Additional file $10(I t)$. Overall, the results indicate that di-nucleotide repeats (GA/TA) were most abundant in both $I b$ and $I t$. The percentage difference in the number of SSRs identified with di-, tri-, and tetra-nucleotide repeats was higher in $I t$ than in $I b(30.8 \%, 43.2 \%$, and $52.5 \%$ higher, respectively). Functional genetic markers such as SSRs are useful in understanding the genetic variation in plants $[66,67]$.

\section{Prediction of Single Nucleotide Polymorphisms (SNPs) and insertions and deletions (InDels) between $I b$ and $I t$} The reads of $I b$ were mapped to the transcripts of $I t$ to identify the unique SNPs for $I b$ and vice versa for It. A total of 1,037,396 (Ib) and 495,931 (It) unique SNPs were identified for each species (Table 6). Within orthologous genes, 254,120 and 89,809 SNPs were identified in $I b$ and It, respectively. Also, 5,669 (Ib) and 883 (It) SNPs were identified within paralogous genes. A list of SNPs is provided in Additional file 11 for $I b$ and Additional file 12 for It. SNPs and InDels, the most abundant genetic variations in the genome, are often exploited for high-throughput genotyping and marker-assisted selection in plants [68]. Recently, Hirakawa et al. [69] reported a list of SNPs in the It genome. In the current study, we identified 103,439 and 69,194 InDels between $I b$ and It. In addition, 18,655 and 11,559 InDels were identified within orthologs between $I b$ and $I t$, respectively. Within paralogs, 197 and 32 InDels were identified in $I b$ and $I t$, respectively (Table 6).

Table 5 Number of SSRs predicted in $I b$ and It

\begin{tabular}{lll}
\hline Number of SSRs & lb & It \\
\hline SSRs predicted by MISA & 20,065 & 26,158 \\
SSRs with unique sets of designed primers & 7,067 & 9,650 \\
\hline
\end{tabular}


Table 6 Number of SNPs and InDels predicted between Ib and It

\begin{tabular}{lll}
\hline Number of SNPs and InDels & 16 & It \\
\hline Total SNPS & $1,037,396$ & 495,931 \\
SNPs within orthologs & 254,120 & 89,809 \\
SNPs within paralogs & 5,669 & 883 \\
Total InDels & 103,439 & 69,194 \\
InDels within orthologs & 18,655 & 11,559 \\
InDels within paralogs & 197 & 32 \\
\hline
\end{tabular}

A list of InDels is provided in Additional file 13 for $I b$ and Additional file 14 for It.

\section{Conclusion}

We compared the root transcriptomes of SR forming cultivated $I$. batatas with its non-tuber-forming wild ancestor, I. trifida. Among paralogous gene sets, genes encoding $R G L$ proteins were identified only in $I b$; we speculate that $R G L$ family proteins may play a role in SR formation in sweetpotato. In addition to the expression of the transcription factor RWP-RK domaincontaining protein in $I b$, other genes that are expressed in $I b$, such as those encoding $\mathrm{K}^{+}$transporters and ERECTA protein kinases, may also play a role in SR formation. qRT-PCR indicated that starch and sucrose metabolism genes such as those encoding ADP-glucose pyrophosphorylase, beta-amylase, and starch synthase, showed enhanced expression in $I b$. By contrast, lignin biosynthetic genes, such as $C A D$ and CoMT, were highly expressed in $I t$ than $I b$. The root transcriptome data obtained in this study may serve as a resource for the development of molecular markers in sweetpotato and may facilitate annotation of the sweetpotato genome.

\section{Methods}

\section{Plant materials and growth conditions}

Five different $I$. batatas (L.) Lam cv. Beauregard ( $I b$ ) plants were grown in pots under greenhouse conditions at the University of Arkansas at Pine Bluff (UAPB), Pine Bluff, AR. Seeds from the non-tuber-forming ancestor $I$. trifida (Kunth) G. Don (It) (PI 540715) were obtained from the USDA-GRIN germplasm center (Plant Genetic Resources Conservation Unit, Griffin, GA). It seeds were scarified using $50 \%$ sulfuric acid and rinsed for five minutes in sterile water. The scarified seeds were germinated on sterile paper and the plants were transplanted in pots and grown under greenhouse conditions. Total roots were collected from 100-day-old plants of $I b$ and $I t$. The FRs and SRs from five $I b$ plants were cleaned, pooled and frozen in liquid nitrogen. Similarly, the total roots of five It plants were cleaned, pooled and frozen for RNA isolation.

\section{RNA extraction}

Total RNA was extracted from roots of $I b$ (designated as $S p 1)$ and $I t$ (designated as Sp2) using Qiagen RNeasy kit (Qiagen, Valencia, CA). RNA samples were subjected to DNase I (1 U/ $\mu \mathrm{l})$ treatment for $15 \mathrm{~min}$., followed by heat inactivation at $65{ }^{\circ} \mathrm{C}$ for $10 \mathrm{~min}$. The extracted RNA was quantified using NanoDrop 2000c (Thermo Fisher Scientific, Wilmington, DE), and the quality was checked by RNA gel electrophoresis (Additional file 15).

\section{cDNA library construction and transcriptome sequencing}

The cDNA library construction and sequencing of RNA from $I b$ and It (without biological controls) were carried out at the UC Davis Genome Center, San Diego, CA. The cDNA libraries were constructed following the manufacturer's protocol (Illumina, Inc., San Diego, CA). Transcriptome sequencing was carried out using the HiSeq 2500 platform (Illumina, Inc., San Diego, CA).

\section{Processing of RNA-seq reads}

The quality of reads was assessed using FastQC (Version 0.10.0). All reads, after removing the adapter, were used for assembly without quality filtering, since at least $90 \%$ of reads passed the minimum quality score of Q30. Reads from $I b(S p 1)$ and $I t(S p 2)$ were assembled separately with Trinity (Version r2012-10-15) using default parameters [70]. Trinity assembly of $I b$ reads resulted in 240,915 contigs while It reads resulted in 366,513 contigs. The reads were mapped back to the assembled transcripts and isoform percentage was calculated using Trinity-RNA-seq by Expectation Maximization (RSEM) [70]. Redundant contigs were filtered from $I b$ and $I t$ using an optimized assembly method [71] in two steps: i) selecting a highly covered isoform for each unique component-subcomponent from Trinity output based on the RSEM results and ii) post-assembly transchimera cleanup using the BLASTX results against nonredundant (nr) protein database. These steps reduced the number of contigs from 240,915 to 98,317 transcripts for $I b$ and from 366,513 contigs to 275,044 transcripts for $I t$. The percentage of redundant contigs was $40.8 \%$ and $75.0 \%$ for $I b$ and $I t$, respectively. The filtered transcripts were used for further analysis. Likely coding sequences (ORFs) were predicted from filtered Trinity transcripts using TransDecoder located within trinityplugins. This helped to predict longest putative ORFs from set of transcripts, out of which best scoring ORFs were selected based on Markov model (log likelihood ratio based on coding/non-coding) in each of six possible reading frames. Thus, ORFs were predicted from the filtered transcripts of both $I b$ and $I t$. We also extracted FPKM values generated by RSEM for the genes of interest. 
Identification of paralogous and orthologous groups

The best coding ORFs were used for identification of orthologs using OrthoMCL [72]. All proteins derived from best coding ORFs were first compared against each other by all-vs-all BLASTP search. BLAST was performed using BLOSUM62 matrix, e-value cutoff of 1.0E-5, and masked for low complexity regions. For all matching pairs of sequences "percent match length" score was calculated and all pairs with less than $50 \%$ scores were eliminated. A network of such sequence pairs across and within species was used to determine orthologous (similar set of sequences between $I b$ and $I t$ ) and paralogous (similar set of sequences within $I b$ or $I t$ ) sequences. All ortholog, paralog pairs identified were then clustered using Markov Clustering (MCL) program (orthoMCL). Cluster group IDs for both paralogs and orthologs are shown in Additional files 3,4 and 5 .

\section{Functional annotation of transcripts}

The filtered transcripts were classified into functional categories using different databases and tools. BLASTX was carried out of $I b$ and $I t$ transcripts against nonredundant database (nr), Arabidopsis protein database (The Arabidopsis Information Resource, TAIR10), Cassava protein database (ftp://ftp.jgi-psf.org/pub/compgen/phyto zome/v9.0/Mesculenta) and potato protein database (ftp:// ftp.jgi-psf.org/pub/compgen/phytozome/v9.0/Stuberosum); and BLASTN against the sweet potato gene index database (https://research.cip.cgiar.org/confluence/display/ SPGI/Home). Both BLASTX and BLASTN were carried out with e-value cutoff of $10-3$ and other default parameters. Transcripts with the best coding ORFs were predicted and additional annotation from trinotate was generated using databases such as Swissprot, PFAM, Protein signal prediction as well as EMBL Uniprot eggNOG and gene ontology (GO). Protein related information was added from PANTHER database based on BLAST hits to the Arabidopsis database. GO classification analysis was carried out using the GO Slim database [58] again based on Arabidopsis database. Based on level 3 category of GO classification, the transcripts were grouped into biological process, molecular function, and cellular component. The percentage of transcripts involved in each category was calculated based on the number of transcripts observed for individual functions versus the total number of transcripts (Fig. 4). Pathway information was added using information from TAIR10 database and DAVID (Fig. 5) [59, 60].

\section{Quantitative Reverse-transcriptase PCR (qRT-PCR)}

qRT-PCR analysis was conducted using StepOnePlus (Applied Biosystems, Carlsbad, CA); cDNA was synthesized from the total RNA used for sequencing analysis. Two-step cDNA conversion was carried out using a high-capacity cDNA reverse transcription kit according to the manufacturer's instructions (Life Technologies, Foster City, CA). First-strand cDNA was synthesized using 10x reverse transcription buffer $(2.0 \mu \mathrm{l}), 100 \mathrm{mM}$ dNTP mix $(0.8 \mu \mathrm{l}), 10 \mathrm{x}$ RT random primers $(2.0 \mu \mathrm{l})$, MultiScribe reverse transcriptase-50 U/ $\mu \mathrm{l}(1.0 \mu \mathrm{l})$, and RNA (500 ng). The reaction was carried out at $25{ }^{\circ} \mathrm{C}$ for $10 \mathrm{~min}$., followed by $37{ }^{\circ} \mathrm{C}$ for $120 \mathrm{~min}$. and $85^{\circ} \mathrm{C}$ for $5 \mathrm{~min}$. Subsequently, second-strand cDNA synthesis was carried out in a $10-\mu \mathrm{l}$ reaction mixture consisting of 1.0 $\mu \mathrm{l}$ 1:1 diluted first-strand cDNA, 2x Fast SYBR Green mix $(5.0 \mu \mathrm{l}), 900 \mathrm{nM}$ of each primer $(0.8 \mu \mathrm{l})$, and $2.4 \mu \mathrm{l}$ of nuclease-free water using MicroAmp optical 96-well reaction plates. The experiment was conducted with three biological replicates and two technical replicates for both $I b$ and $I t$. The sweetpotato $\beta$-tubulin gene was used as an endogenous control, and gene expression levels were determined using the $\Delta \Delta \mathrm{Ct}$ method [73]; $\Delta \Delta \mathrm{Ct}$ was calculated by comparing the $\Delta \mathrm{Ct}$ values of $I b$ and $I t$.

\section{Simple sequence repeats discovery}

SSRs were predicted from filtered transcripts of $I b(S p 1)$ and It (Sp2) using MISA software (Version 1.0) with default parameters (Table 5). Primers were designed for the predicted SSRs using Primer3 [74]. The forward and reverse primers were parsed using custom Perl script followed by filtering low-complexity primer sequences using SSRfinder to obtain a unique set of primers for predicted SSRs. A custom Perl script was used to extract repeat information such as SSR type, SSR size, and SSR start and end positions for the predicted SSRs with unique sets of primers and associated annotation information for Ib (Additional file 9) and It (Additional file 10).

\section{Discovery of single nucleotide polymorphisms and InDels} $I b$ and $I t$ reads were mapped against both $I t$ and $I b$ genes using Burrows-Wheeler Aligner (BWA) [75]. As the read coverage was very high and SNP calling programs failed to call SNPs for very high density, Picard (Version 1.107) 'MarkDuplicates' was used to remove the duplicate reads. About $60 \%$ of reads were marked as duplicate by Picard and were not considered for SNP calling. SNP and InDel calling was carried out with GATK (Version 3.1.1) [76] and Samtools (Version 0.1.18) [77] with all default parameters except for the following options (-baq, $-\mathrm{mbq}=20$, $\mathrm{mmq}=10$, stand_call_conf $=50$, stand_emit_conf $=30$ for GATK and $-\mathrm{Q}=20,-\mathrm{q}=10$ and $-\mathrm{C}=50$ for Samtools). Custom perl scripts were used for further processing to denote specifically unique and common SNPs predicted by GATK and Samtools. Additional filtering of GATK predicted SNPs were filtered with GATK filters such as FisherStrand (>60), Mapping Quality (MQ <40), HaplotypeScore $(>13)$, MQRankSum $(<-12.5)$ and ReadPosRankSum $(<-8)$. InDels 
were filtered with additional filters such as ReadPosRankSum $<-20.0$ and FS $>200.0$. Filtered SNPs and InDels were not removed from final set, however SNPs and InDels which passed the filters were labelled as "PASS" in "FILTER" columns while SNPs and InDels that failed to pass filters have blank "FILTER" column. Annotation and ortholog/paralog information were also added to the SNPs (Additional file 11 for $I b$ and Additional file 12 for $I t$ ) and InDels (Additional file 13 for $I b$ and Additional file 14 for $I t)$.

\section{Additional files}

Additional file 1: BLAST annotation and Gene Ontology (GO)

Additional file 2: BLAST annotation and Gene Ontology (GO) classification of I. trifida contigs (Sp2). (ZIP 42.9 MB)

Additional file 3: Paralogous genes identified in 1. batatas (Sp1). (XLSX 16 KB)

Additional file 4: Paralogous genes identified in 1. trifida (Sp2). (XLSX $285 \mathrm{~KB})$

Additional file 5: Orthologous genes identified between I. batatas (Sp 1) and I. trifida (Sp2). (XLSX 394 KB)

Additional file 6: Primer sequences used for quantitative reversetranscription PCR (qRT-PCR). (XLSX $12.5 \mathrm{~KB}$ )

Additional file 7: Functional annotation of I. batatas (Sp1) transcripts using DAVID. (XLSX 5.85 MB)

Additional file 8: Functional annotation of I. trifida (Sp2) transcripts using DAVID. (XLSX 12.4 MB)

Additional file 9: SSRs and primers predicted in 1. batatas (Sp 1). (XLSX 5.29 MB)

Additional file 10: SSRs and primers predicted in 1. trifida (Sp2).

(XLSX 7.21 KB)

Additional file 11: SNPs identified in 1. batatas (Sp1). (ZIP $190 \mathrm{MB}$ )

Additional file 12: SNPs identified in I. trifida (Sp2). (ZIP 89.7 MB)

Additional file 13: InDels identified in 1. batatas (SP 1). (ZIP $34.3 \mathrm{MB}$ )

Additional file 14: InDels identified in 1. trifida (Sp2). (ZIP $22.5 \mathrm{MB}$ )

Additional file 15: Gel containing RNA samples from I. batatas and I. trifida. (DOCX 1.27 MB)

\section{Abbreviations}

4-CL: 4-coumarate-CoA ligase; ABA: Abscisic acid; CAD: Cinnamyl alcohol dehydrogenase; CaLB: Calcium-dependent lipid binding protein; COMT: Caffeoyl-CoA O-methyltransferase; EPSP: 5-enolpyruvylshikimate-3 phosphate synthase; ERF: Ethylene responsive transcription factor; FR: Fibrous root; Ib: Ipomoea batatas; IbMADS1: Ipomoea batatas MADS-box 1; InDels: Insertions and deletions; It: Ipomoea trifida; KEA5: $\mathrm{K}^{+}$efflux antiporter; KNOX1: Class I knotted1-like homeobox; PAL: Phenylalanine ammonia-lyase; $R G L$ : Rhamnogalacturonate lyase family protein; SNP: Single nucleotide polymorphism; SR: Storage root; SSR: Simple sequence repeat

\section{Acknowledgements}

Authors thank USDA-GRIN for the supply of I. trifida seeds (PI 540715).

\section{Funding}

Funding support for this work was provided to MM by The Plant Powered Production (P3) Center, which was funded wholly or in part by the National Science Foundation (NSF) EPSCoR Program and the Arkansas Science \& Technology Authority (NSF EPSCoR award number: EPS-1003970), and USDA-NIFA Capacity Building Grant (2014-38821-22460).

\section{Availability of data and material}

Seeds from non-tuber-forming ancestor I. trifida (Kunth) G. Don (It) (PI 540715) may be obtained from the USDA-GRIN germplasm center (Plant Genetic Resources Conservation Unit, Griffin, GA, U.S.A.); and plant material for the cultivated I. batatas (L.) Lam cv. Beauregard (Ib) can be obtained from the corresponding author. Data presented in the manuscript are provided in Additional files 1-15. All sequence data of Ib (designated as Sp1) and It (designated as Sp2) from this article have been deposited in the Sequence Read Archive (SRA) at the NCBI database under the accession number: SRP090387 (https://www.ncbi.nlm.nih.gov/sra/?term=SRP090387).

\section{Author's contributions}

MM, SKP and VK conceived and designed the experiments; SKP performed the experiments; JT, KB and SKP analyzed the data; SKP, MM, VK, JT and KB wrote the manuscript. All authors read and approved the final manuscript.

\section{Competing interests}

The authors declare that they have no competing interests.

\section{Consent for publication}

Not applicable.

Ethics approval and consent to participate

Not applicable.

\section{Author details}

'Department of Agriculture, University of Arkansas at Pine Bluff, Pine Bluff, Arkansas, USA. ${ }^{2}$ Bioinformatics Core, Purdue University, West Lafayette, Indiana, USA. ${ }^{3}$ Center for Integrated Biological and Environmental Research (CIBER), Delaware State University, Dover, Delware, USA. ${ }^{4}$ Molecular Genetics and Epigenomics Laboratory, College of Agriculture \& Related Sciences, Delaware State University, Dover, Delware, USA.

Received: 14 July 2016 Accepted: 10 December 2016 Published online: 13 January 2017

References

1. Ziska LH, Runion GB, Tomecek M, Prior SA, Torbet HA, Sicher R. An evaluation of cassava, sweet potato and field corn as potential carbohydrate sources for bioethanol production in Alabama and Maryland. Biomass Bioenergy. 2009;33:1503-8.

2. Firon $N$, LaBonte $D$, Villordon $A, K$ Kfir $Y$, Solis $Y$, Lapis E, Perlman TS, DoronFaigenboim A, Hetzroni A, Althan L, Nadir LA. Transcriptional profiling of sweetpotato (Ipomoea batatas) roots indicates down-regulation of lignin biosynthesis and up-regulation of starch biosynthesis at an early stage of storage root formation. BMC Genomics. 2013;14:460.

3. Villordon AQ, Ginzberg I, Firon N. Root architecture and root and tuber crop productivity. Trends PI Sci. 2014;19:419-25.

4. Villordon AQ, LaBonte DR, Firon N, Kfir Y, Schwartz A, Pressman E. Characterization of adventitious root development in sweetpotato. Hortsci. 2009:44:651-5.

5. Togari Y. A study of tuberous root formation in sweet potato. Bul Nat Agr Expt Sta Tokyo. 1950;68:1-96.

6. Wilson LA, Lowe SB. The anatomy of the root system in West Indian sweet potato [pomoea batatas (L.) Lam.] cultivars. Ann Bot. 1973;37:633-43.

7. Matsuo T, Yoneda T, Itoo S. Variations in the levels of major free cytokinins and free abscisic acid during tuber development of sweet potato. J Plant Growth Regul. 1988;7:249-58.

8. Matsuo $\mathrm{T}$, Yoneda $\mathrm{T}$, Itoo $\mathrm{S}$. Identification of free cytokinins and the changes in endogenous levels during tuber development of sweet potato (Ipomoea batatas Lam.). Plant Cell Physiol. 1983;24:1305-12.

9. Nakatani M, Komeichi M. Changes in endogenous indole acetic acid level during development of roots in sweet potato. Jap J Crop Sci. 1992;61:683-4.

10. Wang $Q$, Zhang L, Guan Y, Wang Z. Endogenous hormone concentration in developing tuberous roots of different sweet potato genotypes. Agrl Sci China. 2006;5:919-27.

11. Noh SA, Lee HS, Huh EJ, Huh GH, Paek KH, Shin JS, Bae JM. SRD1 is involved in the auxin-mediated thickening growth of storage root by enhancing proliferation of metaxylem and cambium cells in sweetpotato (Ipomoea batatas). J Exp Bot. 2010;61:1337-49. 
12. Ku AT, Huang YS, Wang YS, Ma D, Yeh KW. IbMADSI (Ipomoea batatas) MADS-box 1 gene) is involved in tuberous root initiation in sweet potato (Ipomoea batatas). Ann Bot. 2008;102:57-67.

13. Tanaka M, Kato N, Nakayama H, Nakatani M, Takahata Y. Expression of class 1 Knotted1-like homeobox genes in the storage roots of sweetpotato (Ipomoea batatas). J Plant Physiol. 2008;165:1726-35.

14. You MK, Hur CG, Ahn YS, Suh MC, Jeong BC, Shin JS, Bae JM. Identification of genes possibly related to storage root induction in sweetpotato. FEBS Lett. 2003:53:101-5.

15. McGregor C. Differential expression and detection of transcripts in sweetpotato (Ipomoea batatas (L.) LAM.) using cDNA microarrays. PhD thesis. Louisiana State University and Agricultural and Mechanical College; 2006. http://etd.Isu.edu/docs/available/etd-05092006-145816/

16. Noh SA, Lee H-S, Kim Y-S, Paek K-H, Shin JS, Bae JM. Down-regulation of the IbEXP1 gene enhanced storage root development in sweetpotato. J Exp Bot. 2013;64:129-42.

17. Wang Z, Fang B, Chen X, Liao M, Chen J, Zhang X, Huang L, Luo Z, Yao Z, Li $Y$. Temporal patterns of gene expression associated with tuberous root formation and development in sweetpotato. BMC Plant Biol. 2015;15:180.

18. Tao X, Gu Y-H, Wang H-Y, Zheng W, Li X, Zhao C-W, Zhang YZ. Digital gene expression analysis based on integrated de novo transcriptome assembly of sweetpotato [lpomoea batatas (L.) Lam.]. PLoS One. 2012;7:e36234.

19. Martin FW, Jones A, Ruberté RM. A wild Ipomoea species closely related to the sweet potato. Eco Bot. 1974;28:287-92.

20. Oración MZ, Niwa K, Shiotani I. Cytological analysis of tetraploid hybrids between sweet potato and diploid Ipomoea trifida (H.B.K.). Don. Theor Appl Genet. 1990;80:617-24

21. Srisuwan S, Sihachakr D, Yakovled SS. The origin and evolution of sweet potato (Ipomoea batatas Lam.) and its wild relatives through the cytogenic approaches. Plant Sci. 2006;17:424-33.

22. Tsuchiya T, et al. Self-incompatibility system of Ipomoea trifida, a wild-type

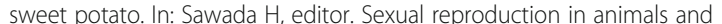
plants, vol. 25. 2014. p. 305-25

23. Schafleitner R, Tincopa LR, Palomino O, Rossel G, Robles RF, Alagon R, Rivera C, Quispe C, Rojas L, Pacheco JA, Solis J, Cerna D, Kim JY, Hou J, Simon R. A sweetpotato gene index established by de novo assembly of pyrosequencing and Sanger sequences and mining for gene-based microsatellite markers. BMC Genomics. 2010;11:604.

24. Wang Z, Fang BP, Chen J, Zhang X, Luo Z, Huang L, Chen X, Li Y. De novo assembly and characterization of root transcriptome using Illumina pairedend sequencing and development of cSSR markers in sweetpotato (Ipomoea batatas). BMC Genomics. 2010;11:726.

25. Altschul SF, Gish W, Miller W, Myers EW, Lipman DJ. Basic local alignment search tool. J Mol Biol. 1990;215:403-10.

26. Solis J, Villordon A, Baishakh N, LaBonte D, Firon N. Effect of drought on storage root development and gene expression profile of sweetpotato under greenhouse and field conditions. J Amer Soc Hort Sci. 2014;139:317-24.

27. Jensen MH, Otten H, Christensen U, Borchert TV, Christensen LLH, Larsen S, Leggio LL. Structural and biochemical studies elucidate the mechanism of rhamnogalacturonan lyase from aspergillus aculeatus. J Mol Biol. 2010;404: 100-11.

28. Willats WGT, McCartney L, Mackie W, Knox JP. Pectin: cell biology and prospects for functional analysis. Plant Mol Biol. 2001;47:9-27.

29. Wolf S, Hematy K, Hofte H. Growth control and cell wall signaling in plants Annu Rev PI Biol. 2012:63:381-407.

30. Aldington S, Fry SC. Oligosaccharins. Adv Bot Res. 1993;19:1-101.

31. Darvill AG, Augur C, Bergmann C, Carlson RW, Cheong JJ, Eberhard S, Hahn MG, Ló VM, Marfá V, Meyer B, Mohnen D, O’Neill MA, Spiro MD, van Halbeek $H$, York WS, Albersheim P. Oligosaccharins-oligosaccharides that regulate growth, development and defence responses in plants. Glycobiology. 1992:2:181-98

32. Vicente AR, Saladié M, Rose JKC, Labavitch JM. The linkage between cell wall metabolism and fruit softening: looking to the future. J Sci Food Agric. 2007:87:1435-48.

33. Hernández GM, Elena M, Rojas M, Lewis AR, Bucio JL, Pena EB, Bello ELS. Plant immunity induced by oligogalacturonides alters root growth in a process involving flavonoid accumulation in Arabidopsis thaliana. J Plant Growth Regul. 2010;29:441-54.

34. Oomen RJ, Doeswijk-Voragen CH, Bush MS, Vincken JP, Borkhardt B, van den Broek LA, Corsar J, Ulvskov P, Voragen AG, McCann MC, Visser RG. In muro fragmentation of the rhamnogalacturonan I backbone in potato
(Solanum tuberosum L.) results in a reduction and altered location of the galactan and arabinan side-chains and abnormal periderm development. Plant J. 2002;30:403-13.

35. Ashley MK, Grant M, Grabov A. Plant responses to potassium deficiencies: a role for potassium transport proteins. J Exp Bot. 2006;57:425-36.

36. Adams E, Shin R. Transport, signaling, and homeostasis of potassium and sodium in plants. J Int Plant Biol. 2014;56:231-49.

37. Elumalai RP, Nagpal P, Reed JW. A mutation in the Arabidopsis KT2/KUP2 potassium transporter gene affects shoot cell expansion. Plant Cell. 2002;14:119-31.

38. Ruan YL, Llewellyn DJ, Furbank RT. The control of single-celled cotton fiber elongation by developmentally reversible gating of plasmodesmata and coordinated expression of sucrose and $\mathrm{K}^{+}$transporters and expansin. Plant Cell. 2001;13:47-60.

39. Ottenschläger I, Wolff P, Wolverton C, Bhalerao RP, Sandberg G, Ishikawa H, Evans M, Palme K. Gravity-regulated differential auxin transport from columella to lateral root cap cells. Proc Natl Acad Sci U S A. 2003;100:2987-91.

40. Shpak ED, Lakeman MB, Torii KU. Dominant-negative receptor uncovers redundancy in the Arabidopsis ERECTA leucine-rich repeat receptor-like kinase signaling pathway that regulates organ shape. Plant Cell. 2003;15:1095-110.

41. Poustka F, Irani NG, Feller A, Lu Y, Pourcel L, Frame K, Grotewold E. A trafficking pathway for anthocyanins overlaps with the endoplasmic reticulum-to-vacuole protein-sorting route in Arabidopsis and contributes to the formation of vacuolar inclusions. Plant Physiol. 2007;145:1323-35.

42. Hattan J, Kanamoto H, Takemura M, Yokota A, Kohchi T. Molecular characterization of the cytoplasmic interacting protein of the receptor kinase IRK expressed in the inflorescence and root apices of Arabidopsis. Biosci Biotech Biochem. 2004;68:2598-606.

43. Wagner TA, Kohorn BD. Wall-associated kinases are expressed throughout plant development and are required for cell expansion. Plant Cell. 2001;13:303-18

44. Waki T, Hiki T, Watanabe R, Hashimoto T, Nakajima K. The Arabidopsis RWPRK protein RKD4 triggers gene expression and pattern formation in early embryogenesis. Curr Biol. 2011;21:1277-81.

45. Chardin C, Girin T, Roudier F, Meyer C, Knapp A. The plant RWP-RK transcription factors: key regulators of nitrogen responses and of gametophyte development. J Exp Bot. 2014;65:5577-87.

46. Remacle C, Eppe G, Coosemans N, Fernandez E, Vigeolas H. Combined intracellular nitrate and NIT2 effects on storage carbohydrate metabolism in Chlamydomonas. J Exp Bot. 2014;65:23-33.

47. Castaings L, Camargo A, Pocholle D, Gaudon V, Texier Y, Boutet-Mercey S, Taconnat L, Renou JP, Daniel-Vedele F, Fernandez E, Meyer C, Krapp A. The nodule inception- like protein 7 modulates nitrate sensing and metabolism in Arabidopsis. Plant J. 2009;57:426-35.

48. Nakamura K, Ohto M, Yoshida N, Nakamura K. Sucrose induced accumulation of $\beta$-amylase occurs concomitant with the accumulation of starch and sporamin in leaf-petiole cuttings of sweet potato. Plant Physiol. 1991:96:902-9.

49. Senthilkumar R, Yeh KW. Multiple biological functions of sporamin related to stress tolerance in sweet potato (Ipomoea batatas Lam). Biotechnol Adv. 2012;30:1309-17.

50. Wang QM, Zhang LM, Wang ZL. Formation and thickening of tuberous roots in relation to the endogenous hormone concentrations in sweetpotato. Sci Agric Sin. 2005:38:2414-20.

51. Baunsgaard $L$, Lütken $H$, Mikkelsen $R$, Glaring MA, Pham $\Pi$, Blennow A. A novel isoform of glucan, water dikinase phosphorylates pre-phosphorylated alpha-glucans and is involved in starch degradation in Arabidopsis. Plant J. 2005:41:595-605.

52. Chen $\mathrm{H}-$ J, Liang S-H, Huang G-J, Lin Y-H. Sweet potato cysteine proteases SPAE and SPCP2 participate in sporamin degradation during storage root sprouting. J Plant Physiol. 2015;186:39-49.

53. Grudkowska M, Zagdańska B. Multifunctional role of plant cysteine proteinases. Acta Biochim Pol. 2004;51:609-24.

54. Edreva A. Pathogenesis-related proteins: Research progress in the last 15 years. Gen Appl Plant Physiol. 2005;31:105-24.

55. Lorenza O, Piqueras R, Jose J. Sánchez-Serrano, Solano R. Ethylene response factor1 integrates signals from ethylene and jasmonate pathways in plant defense. Plant Cell. 2003;15:165-78.

56. Jardim-Messeder D, Caverzan A, Rauber R, Ferreira ES, Margis-Pinheiro M. Galina. Succinate dehydrogenase (mitochondrial complex II) is a source of reactive oxygen species in plants and regulates development and stress responses. New Phytol. 2015;208:776-89. 
57. Mottiar Y, Vanholme R, Boerjan W, Ralph J, Mansfield SD. Designer lignins: harnessing the plasticity of lignification. Curr Opin Biotechnol. 2016;37:190-200.

58. Gene ontology consortium. Gene ontology consortium: moving forward. Nucleic Acids Res. 2015;43:1049-56.

59. Huang DW, Sherman BT, Lempicki RA. Systematic and integrative analysis of large gene lists using DAVID Bioinformatics Resources. Nat Protoc. 2009;4:44-57.

60. Huang DW, Sherman BT, Lempicki RA. Bioinformatics enrichment tools: paths toward the comprehensive functional analysis of large gene lists. Nucleic Acids Res. 2009;37:1-13.

61. Xie F, Burklew CE, Yang Y, Liu M, Xiao P, Zhang B, Qiu D. De novo sequencing and a comprehensive analysis of purple sweet potato (Ipomoea batatas L.) transcriptome. Planta. 2012;236:101-13.

62. Bednarek P, Piślewska-Bednarek M, Svatoś A, Schneider B, Doubsky J, Mansurova M, Humphry M, Consonni C, Panstruga R, Sanchez-Vallet A, Molina A, Schulze-Lefert P. A glucosinolate metabolism pathway in living plant cells mediates broad-spectrum antifungal defense. Science. 2009:323:101-6.

63. Moffatt BA, Ashihara H. Purine and pyrimidine nucleotide synthesis and metabolism. Arabidopsis book. 2002;1:0018.

64. Gao L, Tang J, Li H, Jia J. Analysis of microsatellites in major crops assessed by computational and experimental approaches. Mol Breed. 2003;12:245-61.

65. Thiel T, Michalek W, Varshney RK, Graner A. Exploiting EST databases for the development and characterization of gene-derived SSR-markers in barley (Hordeum vulgare L.). Theo Appl Genet. 2003;106:411-22.

66. Varshney RK, Graner A, Sorrells ME. Genic microsatellite markers in plants: features and applications. Trends Biotechnol. 2005;23:48-55.

67. Varshney RK, Sigmund R, Borner A, Korzun V, Stein N, Sorrells ME, Langridge P, Graner A. Interspecific transferability and comparative mapping of barley EST-SSR markers in wheat, rye and rice. Plant Sci. 2005;168:195-202.

68. Rafalski JA. Novel genetic mapping tools in plants: SNPs and LD-based approaches. Plant Sci. 2002:162:329-33.

69. Hirakawa H, Okada Y, Tabuchi H, Shirasawa K, Watanabe A, Tsuruoka H, Minami C, Nakayama S, Sasamoto S, Kohara M, Kishida Y, Fujishiro T, Kato M, Nanri K, Komaki A, Yoshinaga M, Takahata Y, Tanaka M, Tabata S, Isobe SN. Survey of genome sequences in a wild sweet potato, Ipomoea trifida $(\mathrm{H}$. B. K.) G. Don. DNA Res. 2015;22:171-9.

70. Grabherr MG, Haas BJ, Yassour M, Levin JZ, Thompson DA, Amit I, Adiconis X, Fan L, Raychowdhury R, Zeng Q, Chen Z, Mauceli E, Hacohen N, Gnirke A, Rhind N, Palma FD, Birren BW, Nusbaum C, Toh KL, Friedman N, Regev A. Full-length transcriptome assembly from RNA-Seq data without a reference genome. Nat Biotechnol. 2011;29:644-52.

71. Yang Y, Smith SA. Optimizing de novo assembly of short-read RNA-seq data for phylogenomics. BMC Genomics. 2013;14:328.

72. Fischer S, Brunk BP, Chen F, Gao X, Harb OS, lodice JB, Shanmugam D, Roos $D S$, Stoeckert CJ. Using orthoMCL to assign proteins to orthoMCL-DB groups to cluster proteomics into new ortholog groups. Curr Protoc Bioinformatics. 2011;6:1211-19.

73. Livak KJ, Schmittgen TD. Analysis of relative expression data using real-time quantitative PCR and the $2-\Delta \Delta C$ method. Methods. 2001;25:402-8.

74. Untergrasser A, Cutcutache I, Koressaar T, Ye J, Faircloth BC, Remm M, Rozen SG. Primer3 - new capabilities and interfaces. Nucleic Acids Res. 2012;40:115.

75. Li H, Durbin R. Fast and accurate long-read alignment with BurrowsWheeler transform. Bioinformatics. 2010:26:589-95.

76. McKenna A, Hanna M, Banks E, Sivachenko A, Cibulskis K, Kernytsky A, Garimella K, Altshuler D, Gabriel S, Daly M, DePristo MA. The Genome Analysis Toolkit: a MapReduce framework for analyzing next-generation DNA sequencing data. Genome Res. 2010:20:1297-303.

77. Li H, Handsaker B, Wysoker A, Fennell T, Ruan J, Homer N, Marth G, Abecasis G. Durbin R. 1000 genome project data processing subgroup. The sequence alignment/map (SAM) format and SAMtools. Bioinformatics. 2010;25:2078-9.

\section{Submit your next manuscript to BioMed Central and we will help you at every step:}

- We accept pre-submission inquiries

- Our selector tool helps you to find the most relevant journal

- We provide round the clock customer support

- Convenient online submission

- Thorough peer review

- Inclusion in PubMed and all major indexing services

- Maximum visibility for your research

Submit your manuscript at www.biomedcentral.com/submit
) Biomed Central 